\title{
Preliminary Findings on the Use of Targeted Therapy in Combination with Sodium Phenylbutyrate in Colorectal Cancer after Failure of Second-Line Therapy-A Potential Strategy for Improved Survival
}

\author{
Stanislaw R. Burzynski, Tomasz J. Janicki, Gregory S. Burzynski, Sheldon Brookman \\ Burzynski Clinic, Houston, USA \\ Email: srb@burzynskiclinic.com
}

Received 25 September 2014; revised 20 October 2014; accepted 12 November 2014

Copyright $(2014$ by authors and Scientific Research Publishing Inc.

This work is licensed under the Creative Commons Attribution International License (CC BY).

http://creativecommons.org/licenses/by/4.0/

(c) (i) Open Access

\begin{abstract}
Colorectal cancer (CRC) is the second leading cause of cancer death related mortality with 1.2 million new cases diagnosed annually worldwide. Despite remarkable advances in the treatment of resectable CRC, advanced disease that recurs following initial two lines of chemotherapy, remains incurable. Targeted therapies using a single agent or in combination with other drugs have been tested in a number of clinical trials, with only moderate improvement. Here we present preliminary findings of improved overall survival (OS) using a combination of sodium phenylbutyrate with various targeted and chemotherapeutic agents in stage IV CRC patients who had failed at least two lines of chemotherapy. Results suggest a strategy of simultaneous interruption of signal transduction involving EGFR (VEGF) KRAS-ERK and PI3K-AKT pathways and interference with cell cycle, cancer cell metabolism, maintenance of cancerous stem cells, and promotion of apoptosis. In a group of 15 patients, median OS was higher compared to other third-line therapies (14.7 months compared to between 4.8 and 9.5 months in other studies). Given the understanding that our findings are preliminary, we propose the validation of our initial results using a well-designed phase I/II trial in recurrent advanced colorectal cancer.
\end{abstract}

\section{Keywords}

Colorectal Cancer, Colorectal Cancer Survival, Personalized Targeted Agents, Sodium Phenylbutyrate 


\section{Introduction}

The American Cancer Society statistics for 2014 estimate 136,830 new cases of colorectal cancer (CRC) in the United States [1]. CRC is the third leading cause of cancer death-related mortality with over 50,000 deaths in the United States and fourth worldwide with around 700,000 deaths annually [2]. The importance of CRC among various cancers is also reflected by the number of new treatments introduced in the last three decades, beginning with 5-fluorouracil in the early 1980s and followed by its derivative capecitabine 15 years later. Today, standard first-line treatments include fluorouracil with leucovorin and irinotecan or oxaliplatin, alone or combined with bevacizumab. Cetuximab, the immunoglobulin G1 monoclonal antibody against the epidermal growth factor receptor (EGFR), is effective in combination with irinotecan in patients with metastatic colorectal cancer or as a single agent in patients with metastatic colorectal cancer that progresses even when irinotecan is used. Phase 1 and 2 studies have also shown cetuximab to have activity when added to irinotecan-based therapy or oxaliplatinbased therapy as first-line treatment. Other monoclonal antibodies, bevacizumab, panitumumab, and zivaflibercept have been added to treatment regimens over the last ten or so years, and more recently the multikinase inhibitor regorafenib [3]. As the result of these treatment advances, resectable CRC has become a treatable disease with surgery in the early stages, or with surgery followed chemotherapy. Regimens such as FOLFOX, FOLFIRI, XELOX, and XELIRI are used as first- and second-line treatment for the management of advanced stage IV disease. Unfortunately, few options are available after failure of second-line therapy.

The private practice at the Burzynski Clinic (BC) in Houston, Texas, has focused its interest on treatment of advanced cases of cancer that failed standard therapy. Results of treatment of such patients in both clinical trials and private practice have recently been published and indicate that response rates and overall survival in cases of malignant brain tumor, advanced pancreatic cancer, and mesothelioma may be improved [4]-[12]. Our research attention has been focused on the anti-cancer activity of antineoplastons (ANP) and sodium phenylbutyrate (PB) as treatment adjuncts [13]-[19].

$\mathrm{PB}$, a histone deacetylase (HDAC) inhibitor is the salt of an aromatic fatty acid used in the treatment of urea cycle disorders [17]. It is currently being explored in combination with cytotoxics and other novel drugs. Derived from its HDAC activity, PB is being investigated for use as a potential differentiation-inducing agent in malignant glioma, acute promyelocytic leukemia and many other disorders [19]. ANP is a group of anti-cancer agents that are peptides, amino acid derivatives, and carboxylic acids originally isolated from blood and urine of healthy people [13]-[16]. Some constituents of ANP, namely phenylacetylglutaminate (PG) and phenylacetate (PN) are also metabolites of $\mathrm{PB}$, which in addition to receiving approval for urea cycle disorders is being investigated for adjunctive use in glioma and acute promyelocytic leukemia [10] [16]-[19]. A study of PG and PN on the neoplastic genome of glioblastoma multiforme (GBM) reveals that they affect over 100 genes [20]. Modeling from the GBM genome study and molecular profiling was used to formulate treatment plans for CRC patients.

The evaluation of patients described in this article provides treatment data of 15 patients with advanced CRC who failed at least two lines of standard treatment.

\section{Patients and Methods}

Fifteen subjects were diagnosed with advanced CRC at outside institutions. Radiology and pathology studies were performed by institutions not associated with BC. This group included all consecutive evaluable patients treated at the BC between June 3, 2004 and December 13, 2011.

Laboratory tests were performed by both the laboratory at the BC and outside facilities. Tests included standard blood and urine analysis and the determination of genomic markers. Molecular profiling based on tumor tissue analysis was performed by Foundation Medicine, Cambridge, MA and Caris Life Science, Phoenix, AZ. All patients were provided with treatment details and were required to sign an informed consent document prior to receiving therapy. A treatment plan based on molecular profiling included PB in combination with targeted and chemotherapeutic agents. Patients were treated on an out-patient basis, and after the initial two to four weeks of treatment at the $\mathrm{BC}$, they continued therapy under the care of a local oncologist. Before initiating treatment, a baseline computerized tomography (CT) scan, with and without contrast, and in some patients, a positron emission tomography (PET) scan was performed. The products of two of the largest perpendicular diameters (LPD) of the largest measurable lesions were calculated and totaled providing a baseline evaluation for each study subject. The baseline provided a reference for determining response outcomes to the treatment. Addi- 
tional pretreatment measurements included Karnofsky Performance Status (KPS), vital signs, clinical disease status, demographics, medical history and current medications, physical examination, and EKG. Evaluation of toxicity was performed according to the Common Terminology Criteria for Adverse Events, version 3 (CTCAEv.3). Potential responses to treatment include complete response (CR), partial response (PR), stable disease (SD), and progressive disease (PD). CR required the disappearance of all lesions confirmed at the end of four weeks, PR required $50 \%$ or higher decrease of the LPD of measurable lesions confirmed at four weeks, PD was determined when there were new lesions or when there was an increase over $25 \%$ in the existing lesions, and SD was classified as the status between PR and PD. The duration for each response was measured from the date the criteria of the outcome were first met until the date that PD was first documented. In the case of SD, the duration was measured from the time the therapy commenced.

\section{Results}

\subsection{Patient Demographics}

Patient demographics are described in Table 1. Data on the confirmation of diagnosis, recurrence and response to treatment received are shown in Table 2. All patients had histologically confirmed adenocarcinoma of the colon or rectum with metastases. The majority (93\%) had colon involvement as the primary tumor location and one patient (7\%) had the rectum only as the primary site. The patients typically had multiple metastases with lymph node, liver, and lung involvement. Only one patient did not have prior resection, because the disease was considered too advanced for surgery upon initial evaluation. Four patients (27\%) failed two lines of standard treatment, but the majority of patients had failed three to seven lines of therapy that had included both standard and investigational treatments. Radiation and radiofrequency embolization treatment was provided to each of two patients, respectively.

\subsection{Treatment}

All patients received PB in combination with targeted agents or cytotoxic drugs. Table 3(a) and Table 3(b) describe details of medication doses and treatment duration until the first response was achieved for ten patients who achieved an objective response or SD. Seven patients were treated with multikinase inhibitors pazopanibGlaxoSmithKline, sorafenib-Bayer Healthcare Pharmaceuticals, or dasatinib-Bristol-Myers Squibb Company (pazopanib in 3 patients, sorafenib in 2 patients, and dasatinib in 2 patients). In seven patients, an EGFR inhibitor was prescribed (panitumumab-Amgen Inc. and erlotinib-Genentech Inc. and Astellas Pharma US Inc. in 2 and 5 patients, respectively). Monoclonal antibodies, bevacizumab-Genentech Inc., and trastuzumab-Genentech Inc. were given in four patients (bevacizumab and trastuzumab in 3 and 1 patient, respectively). m-TOR inhibitors were added in three patients (sirolimus-Wyeth Pharmaceuticals Inc.-2 patients, everolimus-Novartis Pharmaceuticals-1 patient). The HDAC inhibitor, vorinostat-Merck was administered in four patients.

Cytotoxic chemotherapy, in addition to targeted therapy, was prescribed in six patients. One patient was given FOLFOX, another patient given FOLFIRI, three patients capecitabine-Genentech, and one each was given oxaliplatin-Sanofi-Aventis US, LLC and a combination of 5-fluorouracil and methotrexate.

\subsection{Responses and Survival}

Partial response, SD and PD were noted in 2 (13.3\%), 8 (53.3\%) and 5 (33.3\%) patients, respectively. One of the PR patients (patient 4) was diagnosed with adenocarcinoma of the colon, moderately differentiated, with extensive metastases in the liver and retroperitoneum. Previously, she had been treated with a continuous infusion of 5-fluorouracil and radiation therapy, and after recurrences underwent laparotomy and colectomy and received FOLFOX 6 along with bevacizumab. Thereafter, the cancer recurred. This patient subsequently underwent combination treatment with PB, FOLFOX, bevacizumab, and erlotinib and achieved a PR (Figure 1).

The second PR patient (Patient 14) was diagnosed with adenocarcinoma of the colon, moderately differentiated, with metastases to the lungs. She had been sequentially treated at a leading cancer institute undergoing a hemicolectomy and treatment with FOLFOX, FOLFIRI, panitumumab, as part of an independent treatment on a phase II study and finally received irinotecan and panitumumab. Overall, her cancer recurred five times and she was sent to hospice. She achieved a PR as a result of treatment with PB, erlotinib, capecitabine, oxaliplatin, bevacizumab, and pazopanib (Figure 2). 
Table 1. Demographics of patients with recurrent colorectal adenocarcinoma, stage IV.

\begin{tabular}{|c|c|c|}
\hline Characteristic & $\mathrm{N}=15$ & $\%$ \\
\hline Age (year) & $\mathrm{N}$ & $\%$ \\
\hline Median & & 58 \\
\hline Range & & $29-80$ \\
\hline \multicolumn{3}{|l|}{ Sex } \\
\hline Male & 10 & 67 \\
\hline Female & 5 & 33 \\
\hline \multicolumn{3}{|c|}{ KPS (Karnofsky performance status score) } \\
\hline 100 & 1 & 7 \\
\hline 90 & 5 & 33 \\
\hline 80 & 3 & 20 \\
\hline 70 & 5 & 33 \\
\hline 60 & 1 & 7 \\
\hline \multicolumn{3}{|l|}{ Colorectal tumor location } \\
\hline Cecum and ascending colon & 2 & 13 \\
\hline Transverse colon & 4 & 27 \\
\hline Rectosigmoid & 8 & 53 \\
\hline Rectum & 1 & 7 \\
\hline \multicolumn{3}{|c|}{ Metastatic sites in addition to colorectal location } \\
\hline Lymph nodes & 11 & 73 \\
\hline Liver & 10 & 67 \\
\hline Lungs & 11 & 73 \\
\hline Peritoneal & 2 & 13 \\
\hline Pleura & 1 & 7 \\
\hline Pelvis & 3 & 20 \\
\hline Adrenal gland & 1 & 7 \\
\hline Surgical procedures & 14 & 93 \\
\hline \multicolumn{3}{|l|}{ Chemotherapy, targeted therapy } \\
\hline 2-line & 4 & 27 \\
\hline 3-line & 4 & 27 \\
\hline 4-line & 4 & 27 \\
\hline 5-line & 2 & 13 \\
\hline 7-line & 1 & 7 \\
\hline Radiation therapy & 2 & 13 \\
\hline Radiofrequency embolization & 2 & 13 \\
\hline
\end{tabular}

As shown in Table 4 comparing survival with other treatments, median OS in our evaluation of 15 patients was 14.7 months and compares more favorably to the other treatments listed, where OS ranged between 4.8 and 9.5 months. The Kaplan-Meier Survival Curve is presented in Figure 3. The Kaplan-Meier analysis was prepared by using the MedCalc Statistical Software version 13.3 (MedCalc Software bvba, Ostend, Belgium; 2014). 
Table 2. Confirmation of diagnosis, recurrence and response-colon cancer.

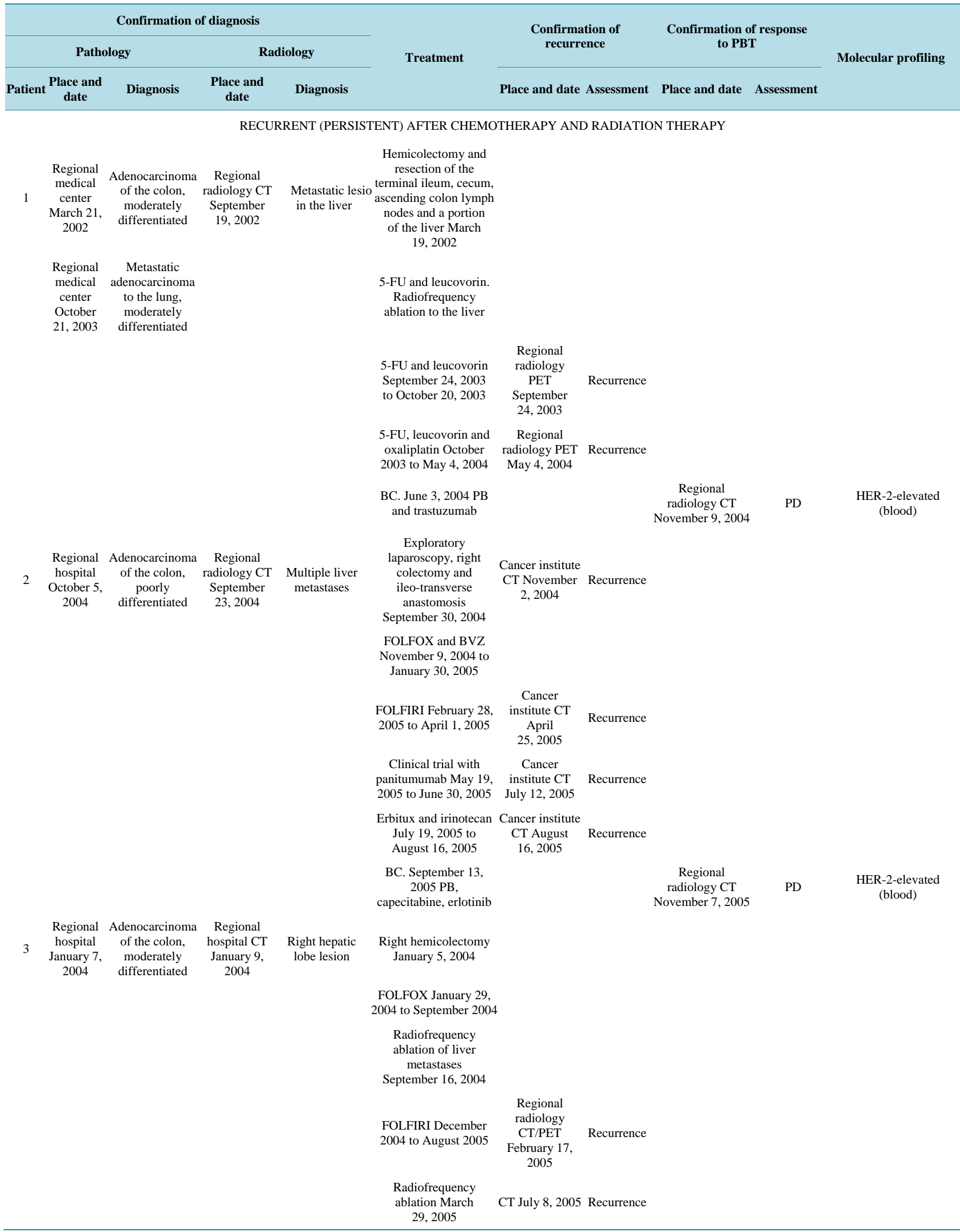




\section{Continued}

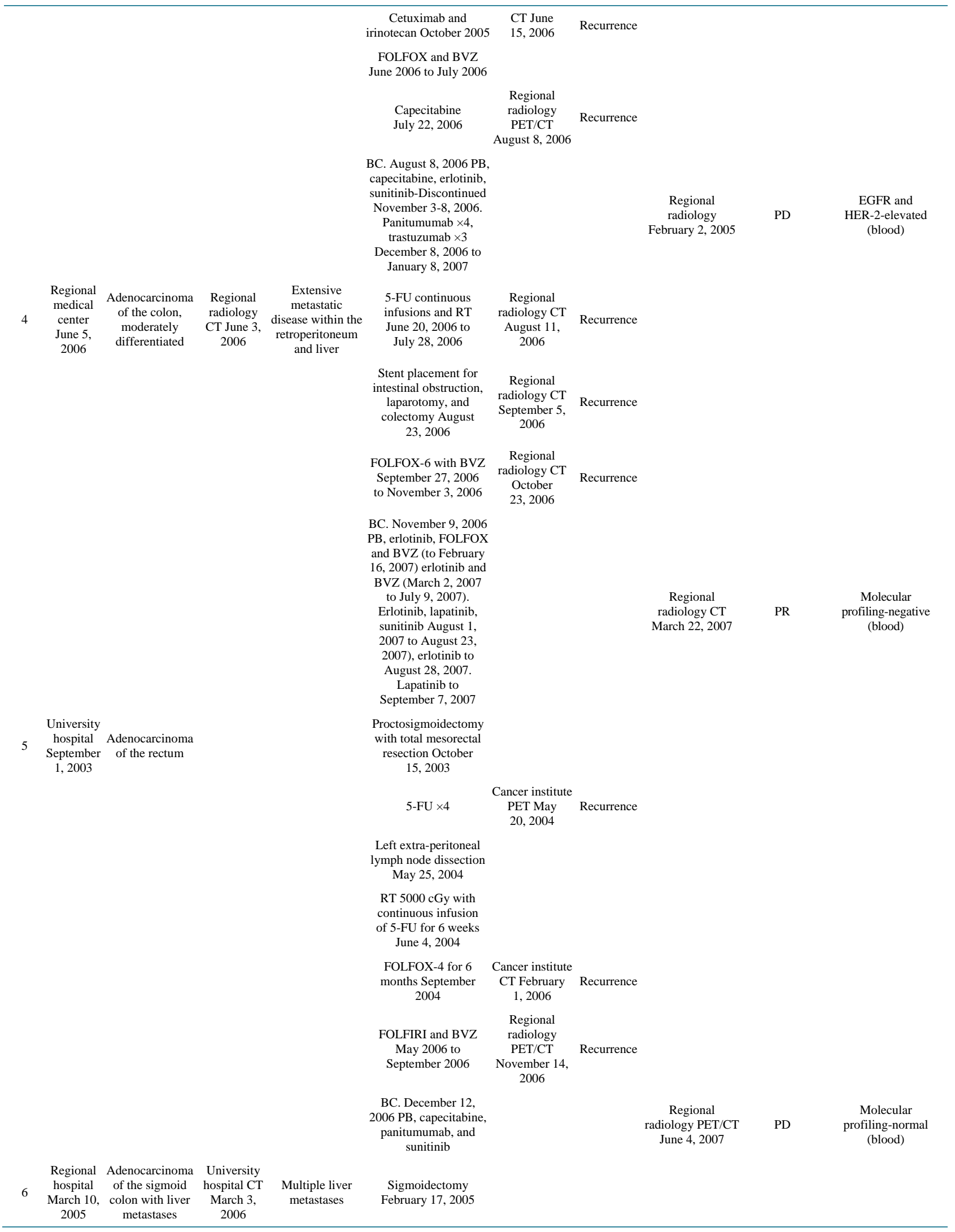




\section{Continued}

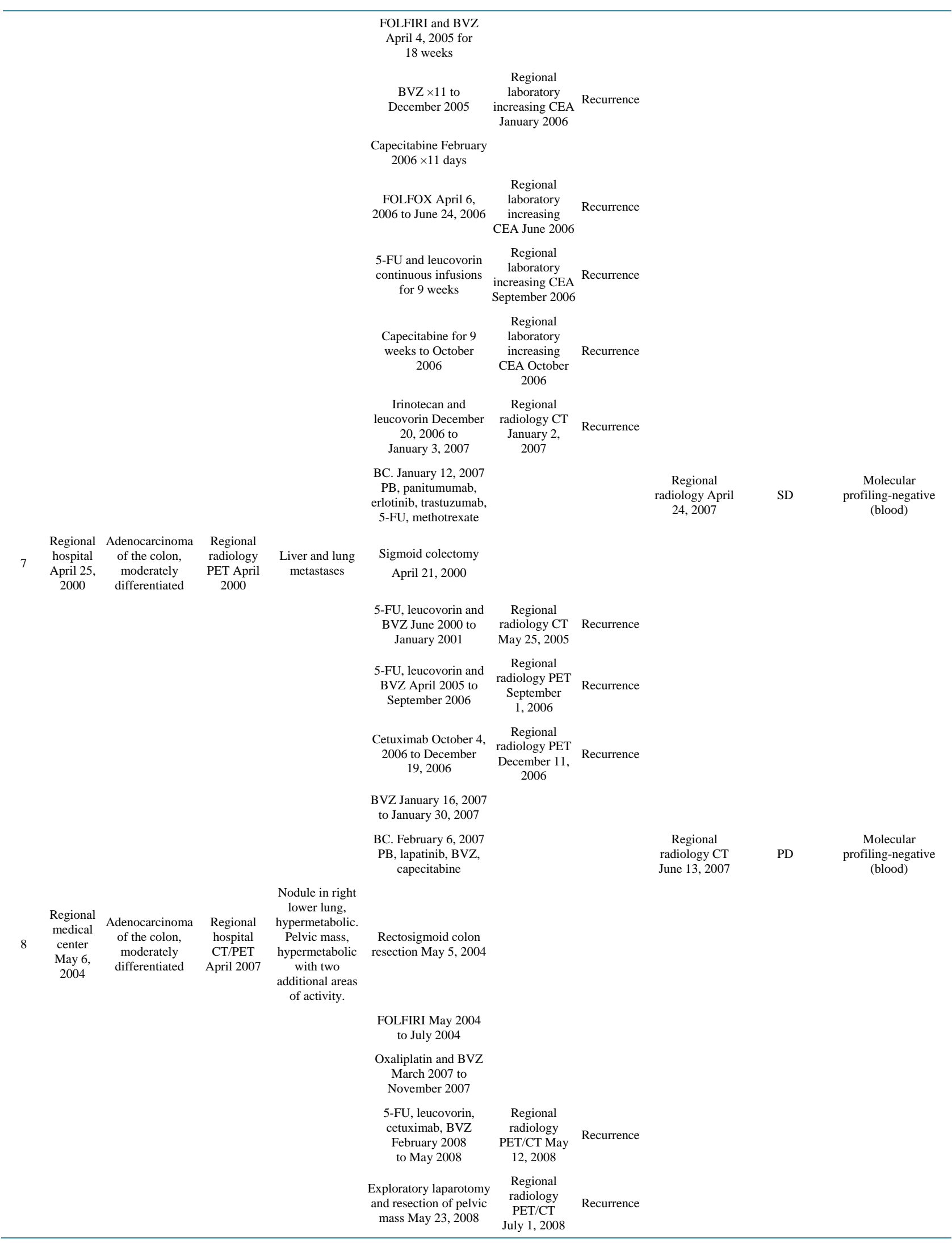




\section{Continued}

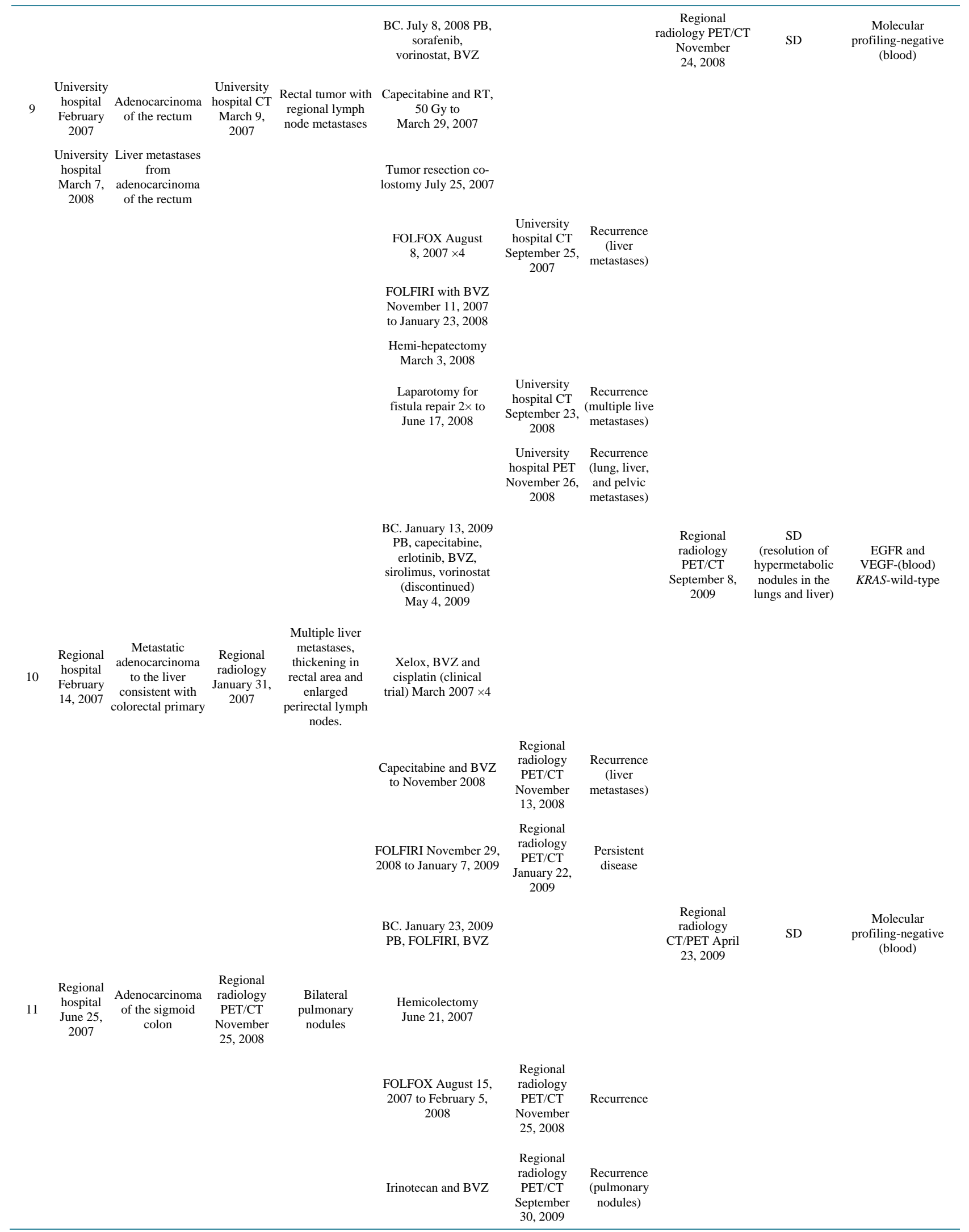




\section{Continued}

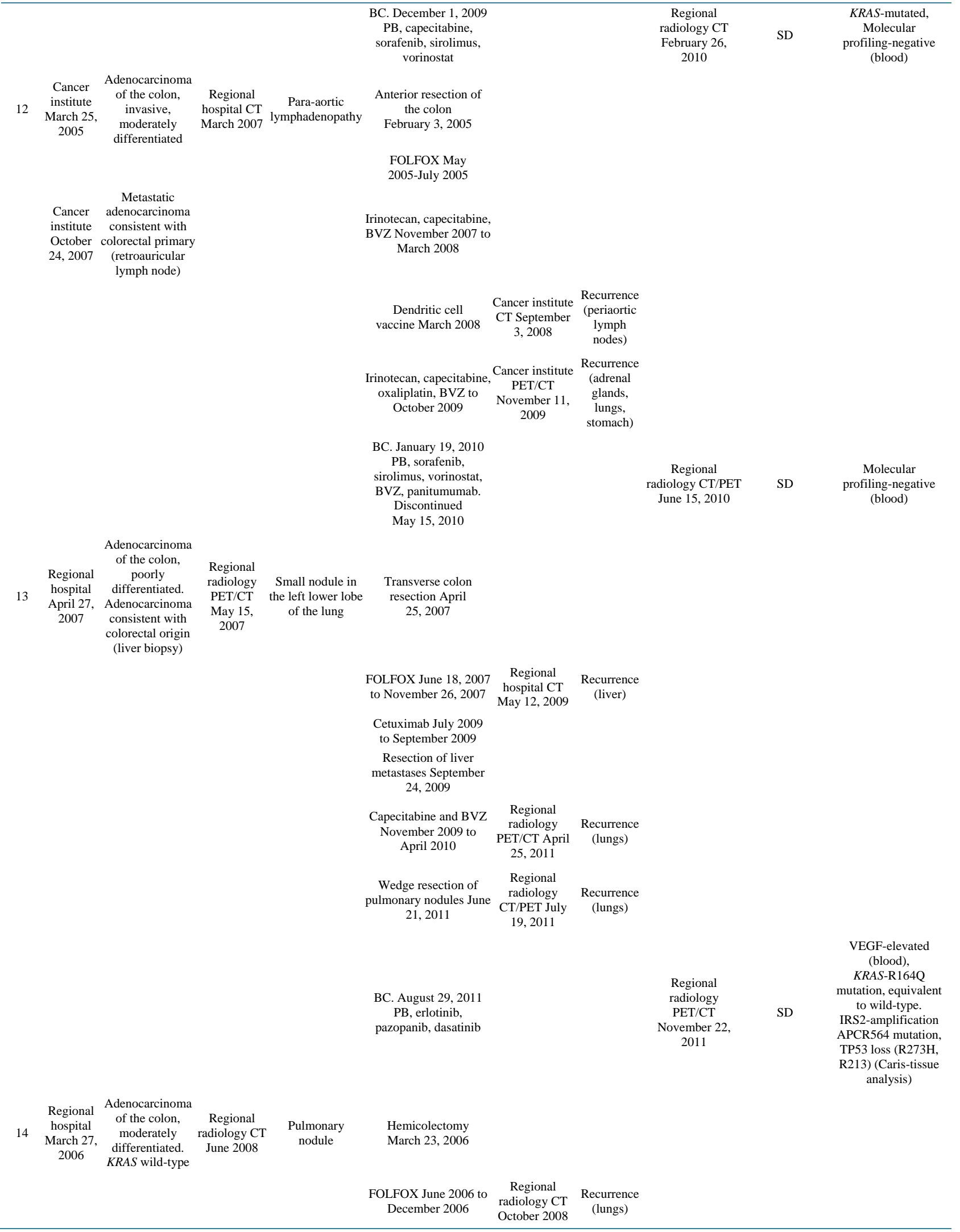




\section{Continued}

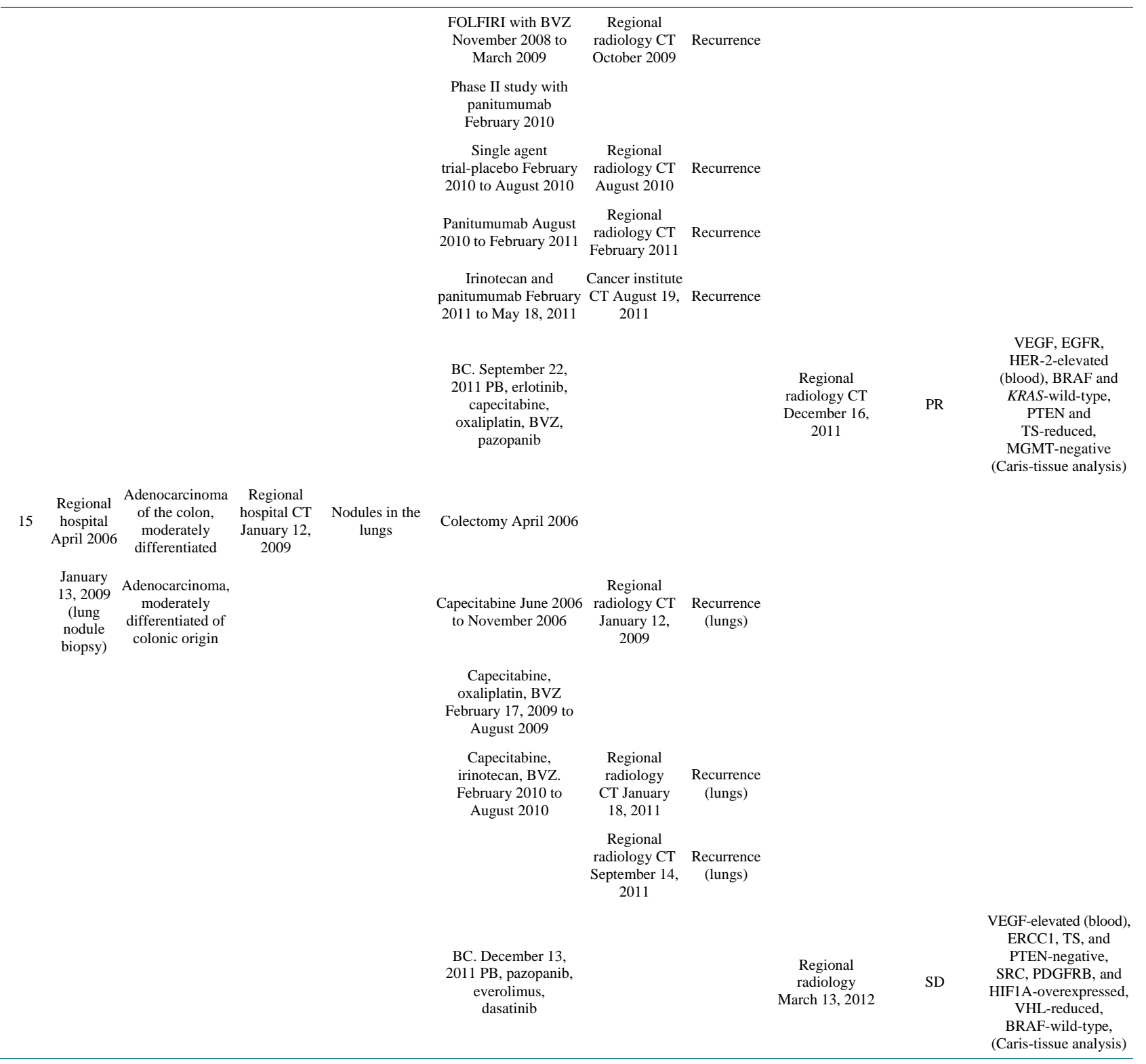

Abbreviations: 5-FU: fluorouracil; BC: Burzynski Clinic; BRAF: serine/threonine protein kinase B-raf; BVZ: bevacizumab; CT: computed tomography; EGFR: epidermal growth factor receptor; ERCC1: excision repair cross-complementation group 1; HER-2: human epidermal growth factor receptor 2; HIF1A: hypoxia inducible factor 1, alpha subunit; IRS2: insulin receptor substrate 2; KRAS: proto-oncogene of the Kirsten murine sarcoma virus: MGMT-o-6-methylguanineDNA methyltransferase; PB: sodium phenylbutyrate, PBT-PB and other drugs; PD: progressive disease; PDGFRB: platelet derived growth factor receptor, beta, PET: positron emission tomography; PR: partial response; PTEN: phosphatase and tensin homolog; RT: radiation therapy; SD: stable disease; SRC: Schmidt-Ruppin; TP53: tumor protein p53; TS: thymidylate synthase; VEGF: vascular endothelial growth factor; VHL: Von Hippel-Lindau.

\subsection{Safety and Adverse Events}

The treatment was generally well-tolerated. There were no Grade 4 toxicities. Grade 3 toxicities included three cases of diarrhea and single cases of thrombocytopenia, hypertension, mucositis, enteritis, and nausea. These adverse drug events (ADEs) were readily reversible within a short time.

\section{Discussion}

This paper describes a potential strategy for a more successful treatment of colorectal cancer after failure of second line therapy. Over 25 years ago, a model for colorectal carcinogenesis was introduced [24]. Epigenetic 


\section{S. R. Burzynski et al.}

Table 3. (a) Doses of targeted medications and duration of treatment until first response; (b) Doses of cytotoxic chemotherapy medications and duration of treatment until first response.

(a)

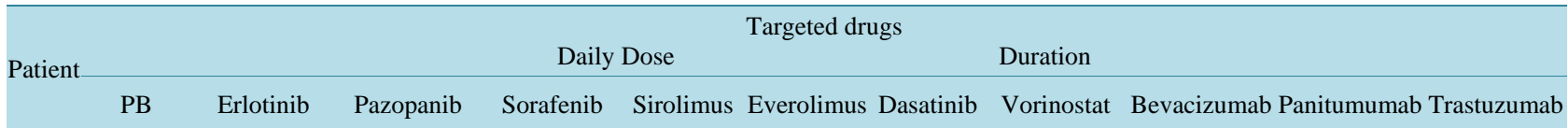

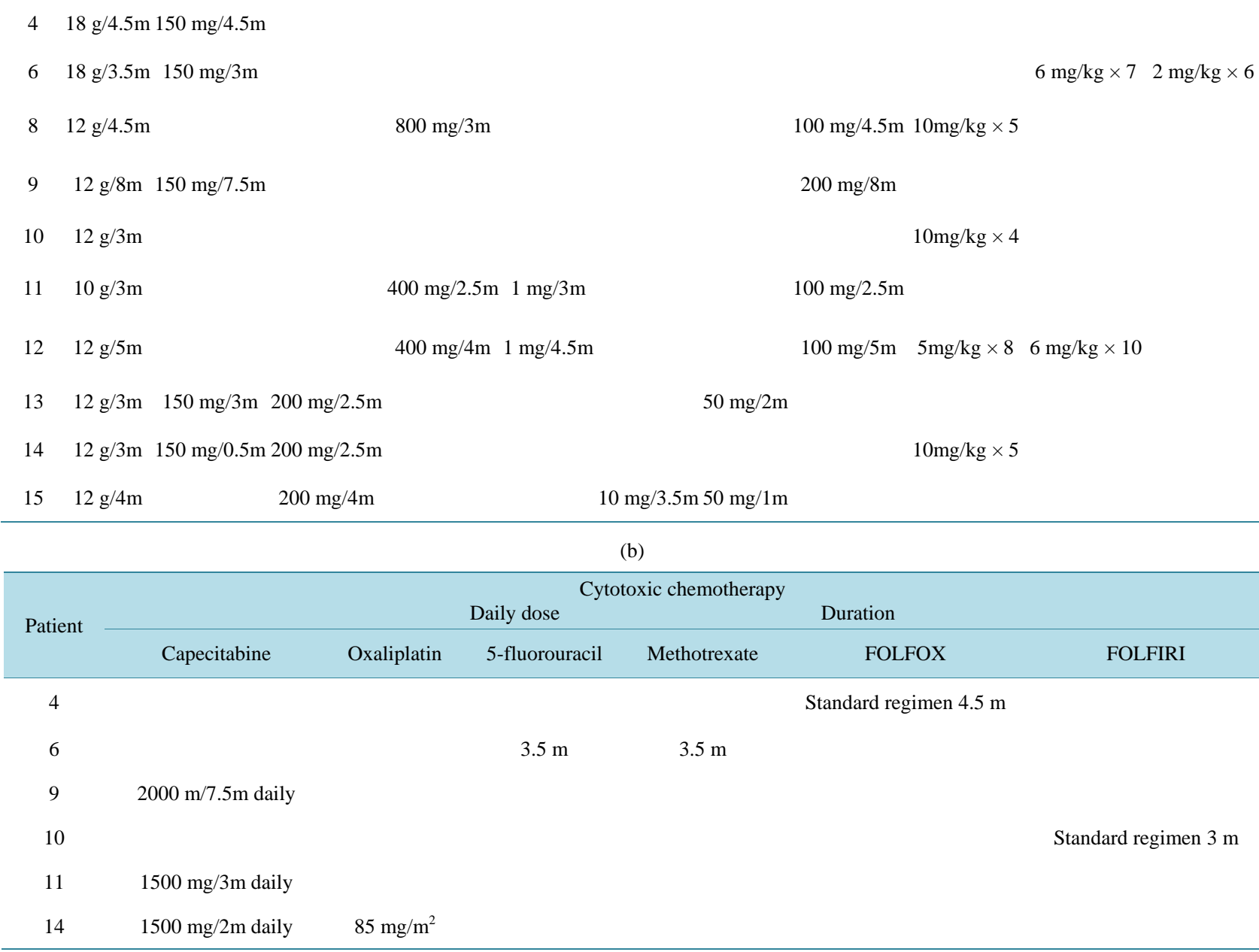

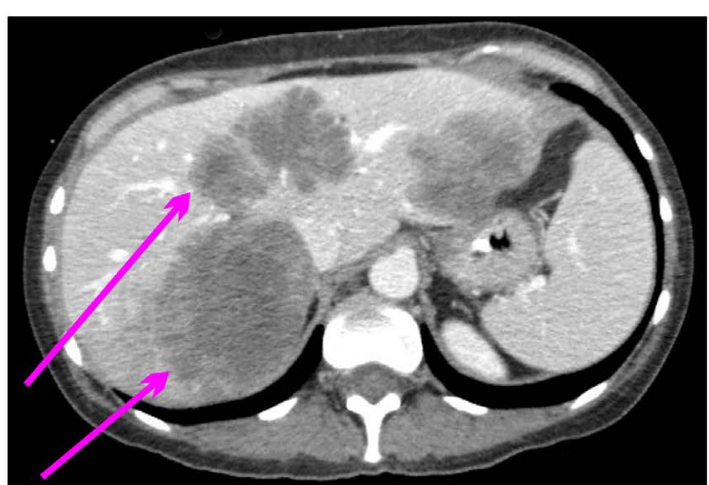

Oct. 23, 2006

Baseline PET scan

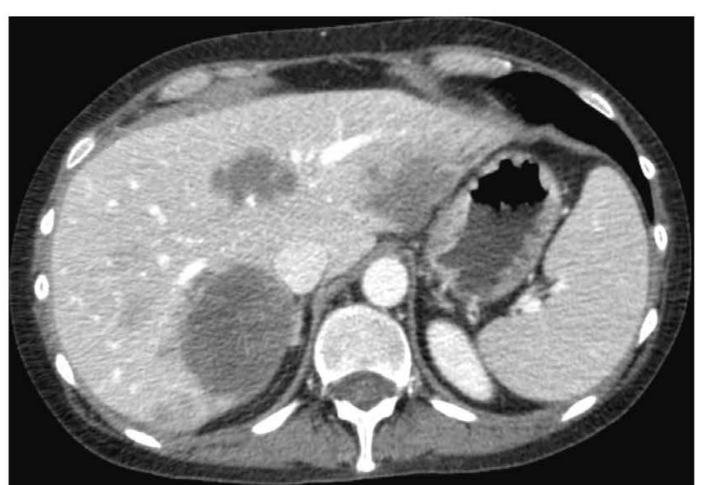

Mar. 22, 2007 Follow-up PET scan

Figure 1. A partial response of liver metastases from colorectal cancer; CT scan, Patient 4. 


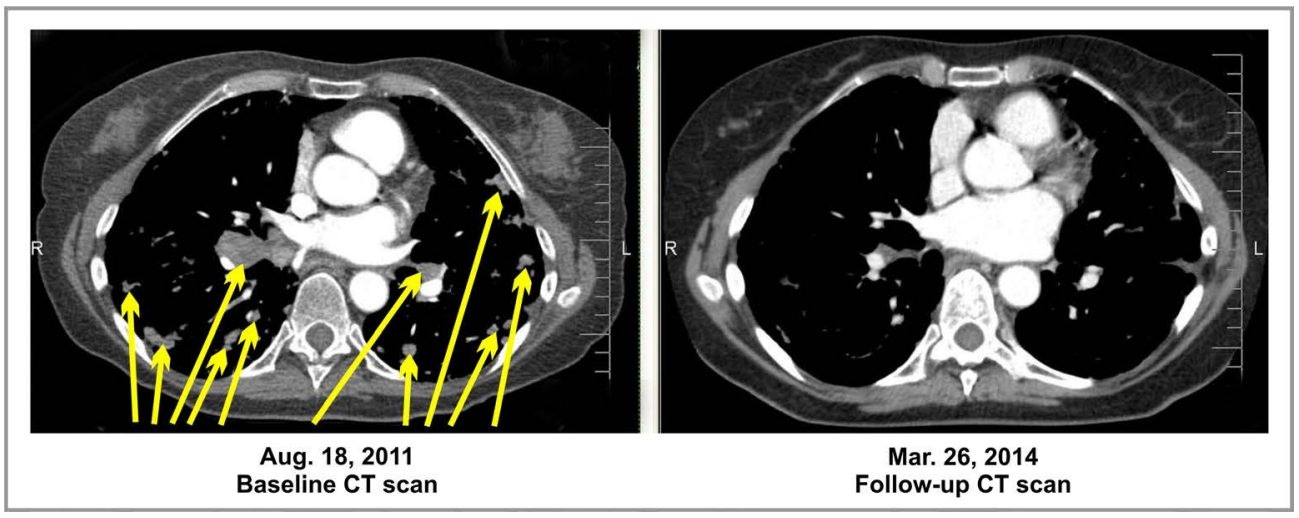

Figure 2. A partial response of pulmonary metastases from colorectal cancer; CT scan, Patient 14.

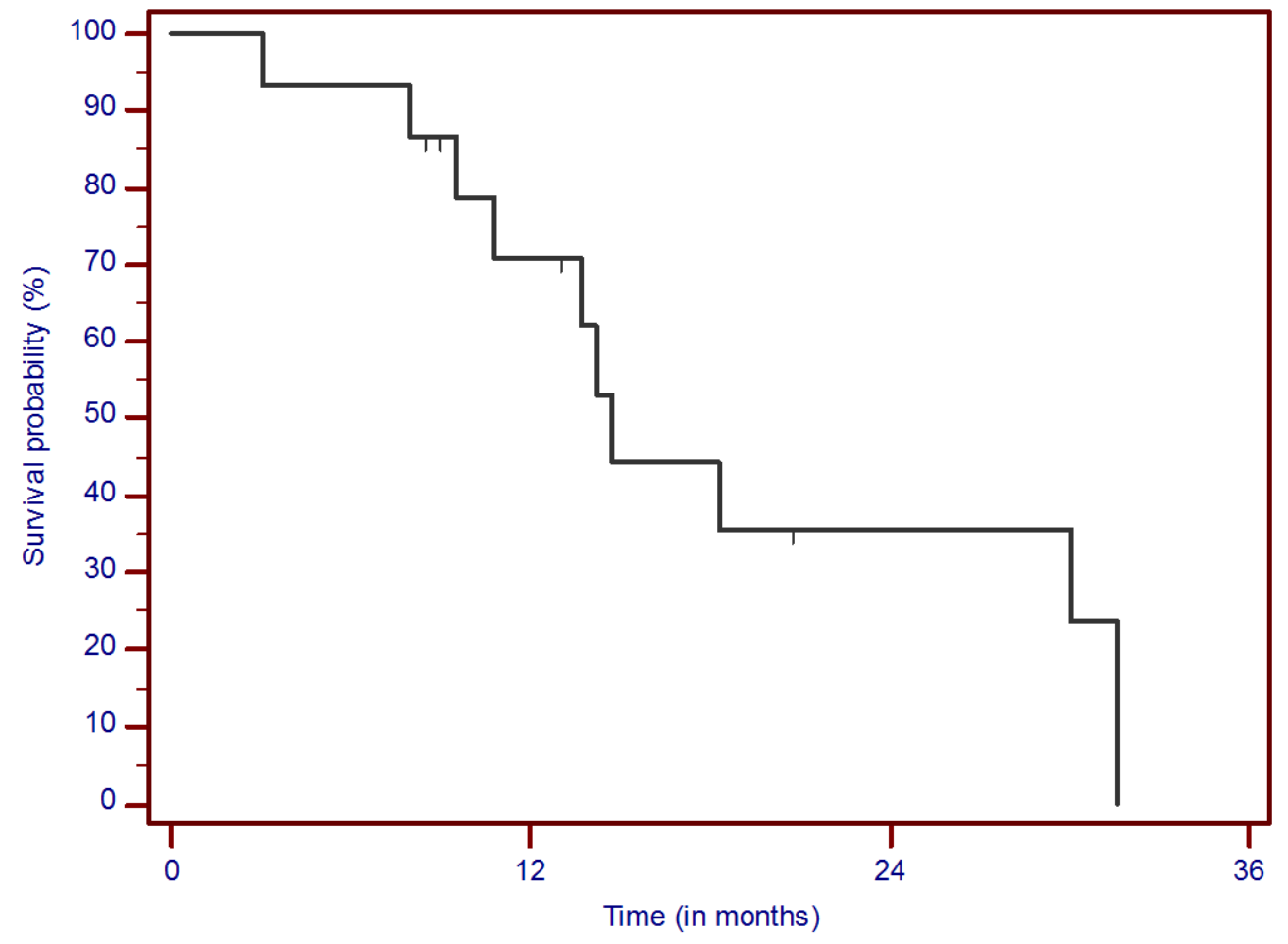

Figure 3. Kaplan-Meier survival curve. Overall survival from treatment start.

changes and mutations in oncogenes and tumor suppressor genes were instrumental in occurrences of gradual abnormalities leading from small adenomatous polyps to invasive adenocarcinoma. Multiple genetic alterations included activation of KRAS, interference in WNT signaling and mutation of TP53 [24]. EGFR signaling played a major role in the development of therapy for CRS [25]. A major breakthrough was the introduction of monoclonal anti-EGFR antibodies, cetuximab and panitumumab [26]. Despite initial success, the resistance toward anti-EGFR antibodies frequently developed due to mutation and amplification of EGFR or genes in the downstream pathways [27]-[30]. A critical member of the downstream RAS pathway is Kerstin-RAS oncogene (KRAS) [31]. The elucidation of the role of KRAS mutations in the efficacy of anti-EGFR therapies became a major area of oncology research. Patients with mutated KRAS seldom responded to cetuximab and panitumumab [32] [33]. Recent data, however, indicate that recurrence in patients with wild-type KRAS treated with anti-EGFR antibodies depends on overgrowth of undetected KRAS mutant cell population, and it was concluded that the majority (93\%) of CRC tumors have KRAS mutations [31] [34]. Differences in the median OS in wild-type and KRAS mutated groups of patients are shown in Table 4 [21] [22]. 
Table 4. Selected clinical studies in advanced colorectal cancer after second-line therapy.

\begin{tabular}{cccc}
\hline Reference & Treatment & Number of patients & OS (months) \\
\hline Karapetis et al. 2008 [21] wild-type K-ras & Cetuximab & 117 & 9.5 \\
Karapetis et al. 2008 [21] mutant K-ras & Cetuximab & 81 & 4.8 \\
Amado et al. 2008 [22] wild-type K-ras & Panitumumab & 124 & 8.1 \\
Amado et al. 2008 [22] mutant K-ras & Panitumumab & 84 & 4.9 \\
Grothey et al. 2013 [23] & Regorafenib & 500 & 6.4 \\
Burzynski et al. 2014 & PB + a targeted combination & 15 & 14.7 \\
\hline
\end{tabular}

Abbreviations: OS-median overall survival.

In addition to monoclonal antibodies that block the extracellular domain of EGFR, the tyrosine kinase inhibitors (TKI), erlotinib and gefitinib that target the intracellular domain of the receptor were assessed in clinical studies [3]. Unfortunately, there were no objective responses and no increased OS in phase II studies with either erlotinib or gefitinib with FOLFIRI [35] [36]. In first-line therapy, however, the addition of erlotinib with bevacizumab following induction with chemotherapy and bevacizumab resulted in statistically significant increase in PFS regardless of KRAS mutation [37].

Due to frequent mutations, KRAS offered a good theoretical therapeutic target. Tipifarnib, an inhibitor of farnesylation of RAS protein failed in CRC clinical trials as a result of conversion from farnesylation to geranylation in cancer cells [38]. BRAF inhibition fared much better. Oral multikinase inhibitor, regorafenib, inhibits BRAF and VEGFR, PDFR $\beta$, FGFR, KIT and RET [39]. Phase III trial with regorafenib confirmed a median OS of 6.4 months [23]. Drug resistance, however, occurs early which is supported by loss of function of PTEN and activation of AKT, and anti-apoptosis action through suppression of BAD [40]. Additional mechanisms of resistance to BRAF inhibitors include secondary KRAS mutations and activation of MEK/ERK [41] [42]. MEK inhibitor selumetinib produced encouraging results, but caused resistance through up-regulation through WNT signaling [43] [44].

The importance of m-TOR in the regulation of growth of cancer cells suggests m-TOR inhibitors are good candidates for clinical trials, a promise that was not fulfilled in studies with sirolimus [45] [46]. An additional concern was the activation of PI3K signaling through a negative feedback loop [47]. The new generation of both $\mathrm{m}$-TOR and PI3K inhibitors demonstrated better results in combination with erlotinib in PTEN negative tumors [48].

Epigenetic mechanisms leading to CRC were studied for a number of years [49]. The agents that promote demethylation of promoters of the tumor suppressor genes and HDAC inhibitors were proposed for treatment of CRC [50]. PB, ANP and vorinostat can be considered in this respect [19] [20].

The failure of combination chemotherapy to eradicate advanced CRC is attributed to persistence of cancerous stem cells (CSC) [51] [52]. Mutations that are crucial in carcinogenesis of CRC, including inactivation of tumor suppressor gene adenomatous polyposis coli (APC) and activation of KRAS, give competitive advantage to stem cells and convert them into the neoplastic process [52]. Genes of developmental pathways participate in the process of formation and maintenance of CSC [53].

Wingless-related integration site (WNT), bone morphogenic protein (BMP), Notch and hedgehog (HH) pathways are critical in this process [53]. Inhibition of WNT signaling through Cox-2 inhibitors celecoxib, indomethacin and aspirin did not produce a significant effect [54] [55]. On the other hand, the activation of non-canonical WNT signaling by HDAC inhibitors inhibited APC mutated CRC cells [56]. This indicates the possible use of vorinostat and PB which in a different study have shown cytotoxic effect against CSC [57]. m-TOR inhibitor everolimus was also found to inhibit WNT signaling [58].

The data from several research centers suggest a general activation of Notch-1 signaling in CRC [59]-[61]. Despite initial promising results, the phase II trials with $\gamma$-secretase inhibitor RO4929097 had little effect [62] [63].

The evidence that inhibition of signal transduction in BMP and HH pathways may find clinical application was not yet presented [53].

Additional approaches to control CRC may include interference in cell cycle, cancer cell metabolism, angiogenesis, and inhibition of apoptosis. These mechanisms were explored in the treatment of recurrent GBM using 
PB in combination with targeted agents [10].

Treatment of advanced CRC after failure of a second-line of standard-of-care therapy creates a challenge for oncologists. The current view on KRAS carcinogenesis recognizes a high background level of KRAS mutation in patients who tested positive for the wild-type gene [31]. Anti-EGFR monotherapies lead to outgrowth of resistant KRAS mutants and recurrence [31].

Based on available research data and our limited experience, we propose the following strategy for the combination of targeted and chemotherapeutic agents (Figure 4 and Figure 5). It is suggested to simultaneously interrupt EGFR (VEGFR)-KRAS-ERK and PI3K-AKT pathways. Patients with wild-type KRAS not previously treated with anti-EGFR antibodies have a reasonable chance to respond to cetuximab or panitumumab in combination with other drugs. Alternatively, based on studies by others, erlotinib can be used synergistically with bevacizumab and chemotherapy regardless of KRAS status [37]. For patients who failed FOLFIRI, capecitabine, and/or oxaliplatin can be reconsidered. In our evaluation, multikinase inhibitors, pazopanib and sorafenib, were used since regorafenib was not yet available. In a new strategy, regorafenib can be used instead. New MEK and

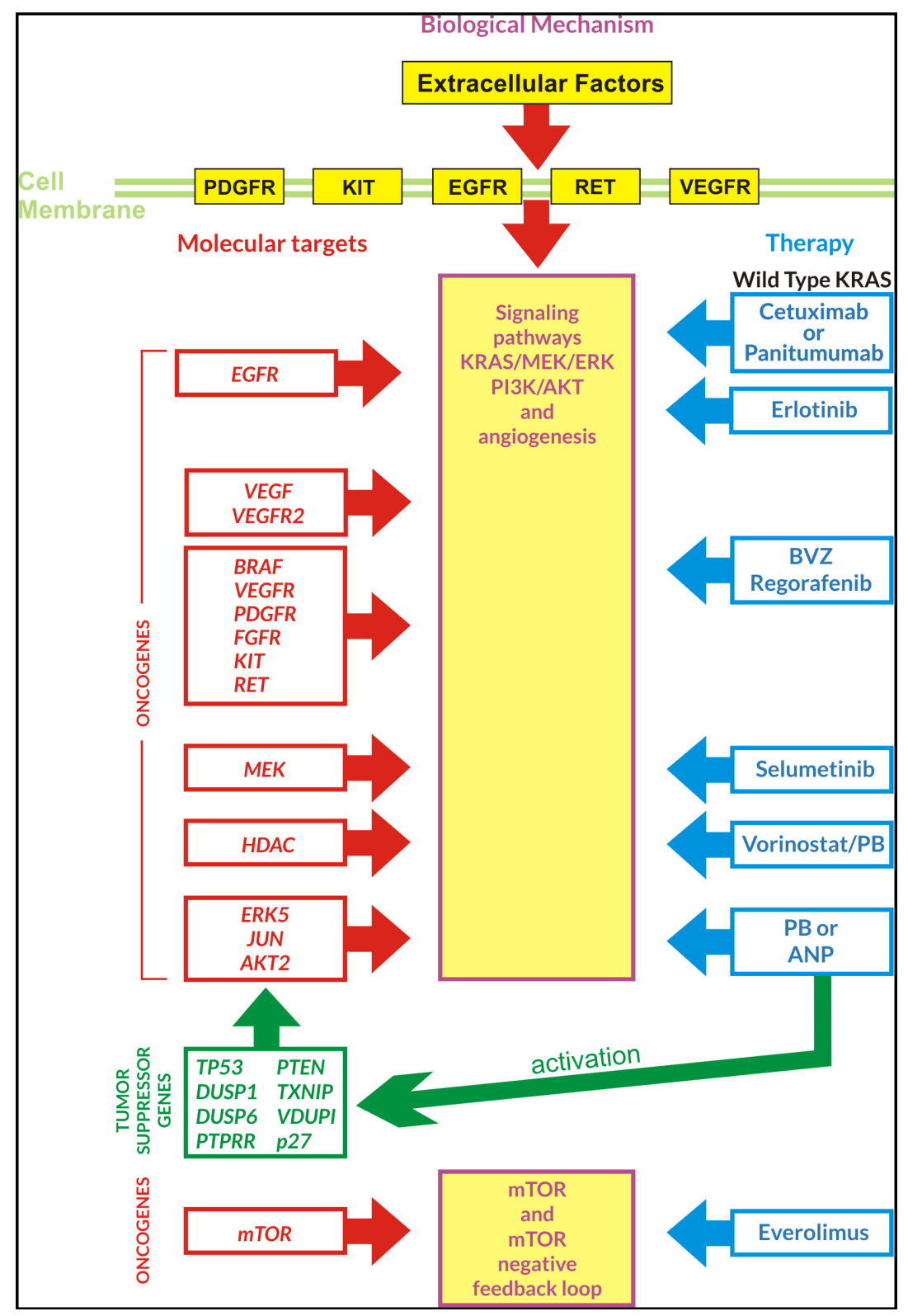

Figure 4. Interruption of transduction pathways by PB and targeted agents. 


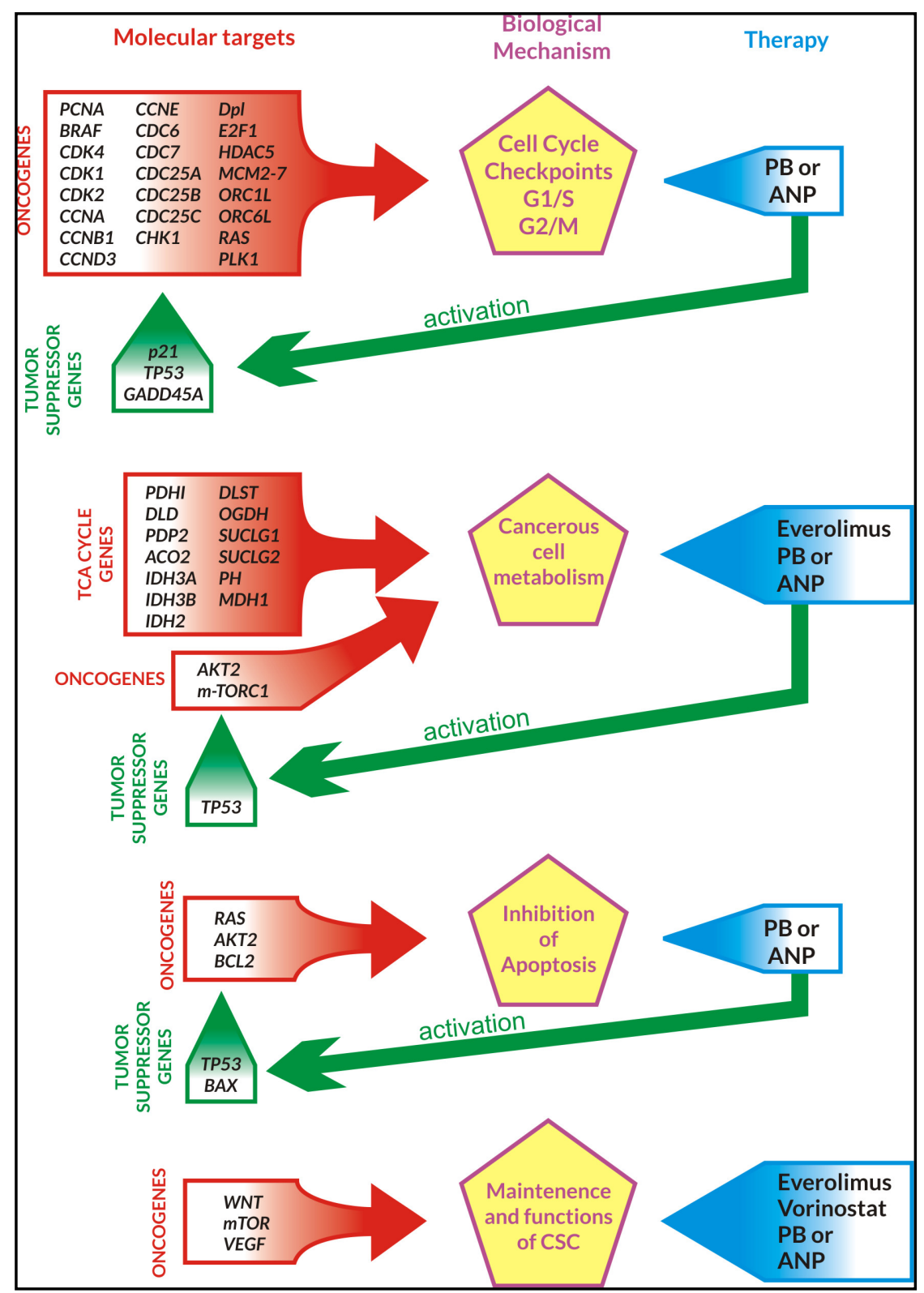

Figure 5. Inhibition of cell cycle, metabolism, maintenance and function of CSC and promotion of apoptosis by PB and targeted agents.

PI3K inhibitors may be considered once they become available. The effect against CSC can be accomplished through a combination of HDAC inhibitors, vorinostat and PB, in conjunction with m-TOR inhibitors, everolimus/sirolimus [57] [58]. Additional targeted agents can be considered based on molecular profiling.

Treatment with PB in combination with targeted agents and chemotherapy appears to provide another option for improved outcomes in patients who failed two lines of standard chemotherapy for advanced CRC. Such combination treatment typically requires a dosage reduction, since toxicities of the drugs can overlap. We understand that the findings with PB in combination with targeted agents and/or chemotherapy are preliminary and we propose validation of these data using a well-designed phase I/II trial in advanced recurrent CRC. This principle for CRC patients who fail prior treatment may also have validity using ANP, which possess overlapping ingredients with metabolites of $\mathrm{PB}$ as they have shown promise in the treatment of various brain tumors, including GBM [4]-[10]. ANP can offer the advantage of higher anticancer activity, since they are available in intravenous dosage form. Randomized, controlled clinical trial in advanced CRC patients comparing intra-arterial 
chemotherapy for the treatment of liver metastases with ANP plus intra-arterial chemotherapy have been successfully completed and have shown 5-year-survival statistics twice as good as the control (intra-arterial chemotherapy). The report is now in press.

\section{Conclusion}

Despite rapid progress in the treatment of CRC, the established standard-of-care for patients who recurred after the second-line chemotherapy provides poor results, with progress being very modest. The use of targeted agents as a single treatment or in combination with chemotherapy has not provided substantial survival benefit. The results reported here are based on a small series of patients who were consecutively admitted for the treatment at $\mathrm{BC}$ during the last few years. This is a retrospective evaluation that shows an increase of median OS and tolerable toxicity compared to other available treatments. The choice of targeted agents was limited when this evaluation began. Furthermore, molecular profiling was in its early stages, providing limited data that were helpful for the design of treatment plans. The group included only evaluable patients, which is typical for a retrospective analysis. The authors realize that results are preliminary and the sample size is small. They should be validated in a larger population by well-designed phase I/II clinical trials with PB or ANP in combination with targeted or chemotherapeutic agents. Caution should be exercised when combining these agents, since no clinical trials have been conducted yet with such combinations. We also propose that future clinical trials include molecular profiling to help select the subgroups of cases of CRC and coordinate genomic changes with responses.

\section{Acknowledgements}

The authors express their appreciation to the additional physicians involved in the care of the patients: Drs. Zanhua Yi, Alejandro Marquis, Robert Weaver, Sheryl Acelar, Lourdes De Leon, and Mohammad Khan. Preparation of the manuscript was provided by Carolyn Powers, Jennifer Pineda, Elizabeth Cleveland, Maria Corzo, and Adam Golunski.

\section{Consent}

Written informed consent was obtained from patients for publication of this case report and accompanying images.

\section{Competing Interests}

All authors are employed by Burzynski Clinic. Dr. Stanislaw R. Burzynski and Dr. Gregory S. Burzynski are shareholders and directors, and Dr. Tomasz J. Janicki is the Vice-President of Burzynski Research Institute, Inc. Dr. Stanislaw R. Burzynski is President of Burzynski Research Institute, Inc., Dr. Gregory S. Burzynski is Vice-President of Burzynski Clinic and Dr. Sheldon Brookman is Director of Pharmaceutical Development of Burzynski Clinic.

\section{References}

[1] Siegel, R., Ma, J., Zou, Z. and Jemal, A. (2014) Cancer Statistics, 2014. CA: A Cancer Journal for Clinicians, 64, 9-29. http://dx.doi.org/10.3322/caac.21208

[2] Jemal, A., Center, M.M., DeSantis, C. and Ward, E.M. (2010) Global Patterns of Cancer Incidence and Mortality Rates and Trends. Cancer Epidemiology, Biomarkers \& Prevention, 19, 1893-1907. http://dx.doi.org/10.1158/1055-9965.EPI-10-0437

[3] Recondo Jr., G., Diaz-Canton, E., De La Vega, M., Greco, M., Recondo Sr., G. and Valsecchi, M.E. (2014) Advances and New Perspectives in the Treatment of Metastatic Colon Cancer. World Journal of Gastrointestinal Oncology, 6, 211-224. http://dx.doi.org/10.4251/wjgo.v6.i7.211

[4] Burzynski, S.R. (2006) Treatments for Astrocytic Tumors in Children: Current and Emerging Strategies. Pediatric Drugs, 8, 167-168. http://dx.doi.org/10.2165/00148581-200608030-00003

[5] Burzynski, S.R., Janicki, T.J., Burzynski, G.S. and Marszalek, A. (2014) The Response and Survival of Children with Recurrent Diffuse Intrinsic Pontine Glioma Based on Phase II Study of Antineoplastons A10 and AS2-1 in Patients with Brainstem Glioma. Childs Nervous System, 30, 2051-2061.

[6] Burzynski, S.R., Janicki, T.J., Burzynski, G.S. and Marszalek, A. (2013) Long-Term Survival (>13 Years) in a Child 
with Recurrent Diffuse Pontine Gliosarcoma: A Case Report. Journal of Pediatric Hematology/Oncology, 36, e433e439. http://dx.doi.org/10.1097/MPH.0000000000000020

[7] Burzynski, S.R., Janicki, T.J., Burzynski, G.S. and Marszalek, A. (2014) A Phase II Study of Antineoplastons A10 and AS2-1 in Children with High-Grade Glioma. Final Report and Review of Recent Trials. Journal of Cancer Therapy, 5, 565-577. http://dx.doi.org/10.4236/jct.2014.56065

[8] Burzynski, S.R., Janicki, T.J. and Burzynski, G.S. (2014) A Phase II Study of Antineoplastons A10 and AS2-1 in Adult Patients with Recurrent Glioblastoma Multiforme. Final Report (Protocol BT-21). Journal of Cancer Therapy, 5, 946-956. http://dx.doi.org/10.4236/jct.2014.510100

[9] Burzynski, S.R., Janicki, T.J., Burzynski, G.S. and Marszalek, A. (2014) A Phase II Study of Antineoplastons A10 and AS2-1 in Children with Recurrent, Refractory or Progressive Primary Brain Tumors. Final Report (Protocol BT-22). Journal of Cancer Therapy, 5, 977-988. http://dx.doi.org/10.4236/jct.2014.510102

[10] Burzynski, S.R., Burzynski, G.S. and Janicki, T.J. (2014) Recurrent Glioblastoma Multiforme-A Strategy for LongTerm Survival. Journal of Cancer Therapy, 5, 957-976. http://dx.doi.org/10.4236/jct.2014.510101

[11] Burzynski, S.R., Janicki, T.J., Burzynski, G.S. and Brookman, S. (2014) Preliminary Findings on the Use of Targeted Therapy in Combination with Sodium Phenylbutyrate in Recurrent Advanced Pancreatic Cancer-A Potential Strategy for Improved Survival. Journal of Cancer Therapy, 5, 1127-1144. http://dx.doi.org/10.4236/jct.2014.512113

[12] Burzynski, S.R., Janicki, T.J., Burzynski, G.S. and Brookman, S. (2014) Preliminary Findings on the Use of Targeted Therapy in Combination with Sodium Phenylbutyrate in Advanced Malignant Mesothelioma, the Strategy for Improved Survival. Journal of Cancer Therapy, 5, 1072-1091. http://dx.doi.org/10.4236/jct.2014.512116

[13] Burzynski, S.R. (1976) Antineoplastons: Biochemical Defense against Cancer. Physiological Chemistry and Physics, 8, 275-279.

[14] Burzynski, S.R. (1986) Antineoplastons-History of the Research (I). Drugs under Experimental and Clinical Research, 12, 1-9.

[15] Burzynski, S.R. (1986) Synthetic Antineoplastons and Analogs. Drugs of the Future, 11, 679-688.

[16] Burzynski, S.R. (2004) The Present State of Antineoplaston Research (1). Integrative Cancer Therapies, 3, 47-58. http://dx.doi.org/10.1177/1534735403261964

[17] Brusilow, S.W., Danney, M., Waber, L.J., Batshaw, M., Burton, B., Levitsky, L., et al. (1984) Treatment of Episodic Hyperammonemia in Children with Inborn Errors of Urea Synthesis. New England Journal of Medicine, 310, 16301634. http://dx.doi.org/10.1056/NEJM198406213102503

[18] Phuphanich, S., Baker, S.D., Grossman, S.A., Carson, K.A., Gilbert, M.R., Fisher J.D., et al. (2005) Oral Sodium Phenylbutyrate in Patients with Recurrent Malignant Gliomas: A Dose Escalation and Pharmacologic Study. NeuroOncology, 7, 177-182. http://dx.doi.org/10.1215/S1152851704000183

[19] Iannitti, T. and Palmieri, B. (2011) Clinical and Experimental Applications of Sodium Phenylbutyrate. Drugs in R\&D, 11, 227-249. http://dx.doi.org/10.2165/11591280-000000000-00000

[20] Burzynski, S.R. and Patil, S. (2014) The Effect of Antineoplastons A10 and AS2-1 and Metabolites of Sodium Phenylbutyrate on Gene Expression in Glioblastoma Multiforme. Journal of Cancer Therapy, 5, 929-945. http://dx.doi.org/10.4236/jct.2014.510099

[21] Karapetis, C.S., Khambata-Ford, S., Jonker, D.J., O’Callaghan, C.J., Tu, D., Tebbutt, N.C., et al. (2008) K-ras Mutations and Benefit from Cetuximab in Advanced Colorectal Cancer. New England Journal of Medicine, 359, 1757-1765. http://dx.doi.org/10.1056/NEJMoa0804385

[22] Amado, R.G., Wolf, M., Peeters, M., Van Cutsem, E., Siena, S., Freeman, D.J., et al. (2008) Wild-Type KRAS Is Required for Panitumumab Efficacy in Patients with Metastatic Colorectal Cancer. Journal of Clinical Oncology, 26, 1626-1634. http://dx.doi.org/10.1200/JCO.2007.14.7116

[23] Grothey, A., Van Cutsem, E., Sobrero, A., Siena, S., Falcone, A., Ychou, M., et al. (2013) Regorafenib Monotherapy for Previously Treated Metastatic Colorectal Cancer (CORRECT): An International, Multicentre, Randomized, Placebo-Controlled, Phase 3 Trial. The Lancet, 381, 303-312. http://dx.doi.org/10.1016/S0140-6736(12)61900-X

[24] Vogelstein, B., Fearon, E.R., Hamilton, S.R., Kern, S.E., Preisinger, A.C., Leppert, M., et al. (1988) Genetic Alterations during Colorectal Tumor Development. New England Journal of Medicine, 319, 525-532. http://dx.doi.org/10.1056/NEJM198809013190901

[25] Efferth, T. (2012) Signal Transduction Pathways of the Epidermal Growth Factor Receptor in Colorectal Cancer and Their Inhibition by Small Molecules. Current Medicinal Chemistry, 19, 5735-5744. http://dx.doi.org/10.2174/092986712803988884

[26] Vivanco, I. and Mellinghoff, I.K. (2010) Epidermal Growth Factor Receptor Inhibitors in Oncology. Current Opinion in Oncology, 22, 573-578. http://dx.doi.org/10.1097/CCO.0b013e32833edbdf 
[27] Hu-Lieskovan, S., Vallbohmer, D., Zhang, W., Yang, D., Pohl, A., Labonte, M.J., et al. (2011) EGF61 Polymorphism Predicts Complete Pathologic Response to Cetuximab-Based Chemotherapy Independent of KRAS Status in Locally Advanced Rectal Cancer Patients. Clinical Cancer Research, 17, 5161-5169. http://dx.doi.org/10.1158/1078-0432.CCR-10-2666

[28] Laurent-Puig, P., Cayre, A., Manceau, G., Buc, E., Bachet, J.B., Lecomte, T., et al. (2009) Analysis of PTEN, BRAF, and EGFR Status in Determining Benefit from Cetuximab Therapy in Wild-Type KRAS Metastatic Colon Cancer. Journal of Clinical Oncology, 27, 5924-5930. http://dx.doi.org/10.1200/JCO.2008.21.6796

[29] Sartore-Bianchi, A., Bencardino, K., Cassingena, A., Venturini, F., Funaioli, C., Cipani, T., et al. (2010) Therapeutic Implications of Resistance to Molecular Therapies in Metastatic Colorectal Cancer. Cancer Treatment Reviews, 36, S1S5. http://dx.doi.org/10.1016/S0305-7372(10)70012-8

[30] Park, J.H., Han, S.W., Oh, D.Y., Im, S.A., Jeong, S.Y., Park, K.J., et al. (2011) Analysis of KRAS, BRAF, PTEN, IGF1R, EGFR Intron 1 CA Status in Both Primary Tumors and Paired Metastases in Determining Benefit from Cetuximab Therapy in Colon Cancer. Cancer Chemotherapy and Pharmacology, 68, 1045-1055. http://dx.doi.org/10.1007/s00280-011-1586-z

[31] Parsons, B.L. and Myers, M.B. (2013) Personalized Cancer Treatment and the Myth of KRAS Wild-Type Colon Tumors. Discovery Medicine, 15, 259-267.

[32] Baldus, S.E., Schaefer, K.L., Engers, R., Hartleb, D., Stoecklein, N.H. and Gabbert, H.E. (2010) Prevalence and Heterogeneity of KRAS, BRAF, and PIK3CA Mutations in Primary Colorectal Adenocarcinomas and Their Corresponding Metastases. Clinical Cancer Research, 16, 790-799. http://dx.doi.org/10.1158/1078-0432.CCR-09-2446

[33] Bando, H., Yoshino, T., Tsuchihara, K., Ogasawara, N., Fuse, N., Kojima, T., et al. (2011) KRAS Mutations Detected by the Amplification Refractory Mutation System-Scorpion Assays Strongly Correlate with Therapeutic Effect of Cetuximab. British Journal of Cancer, 105, 403-406. http://dx.doi.org/10.1038/bjc.2011.247

[34] Molinari, F., Felicioni, L., Buscarino, M., De Dosso, S., Buttitta, F., Malatesta, S., et al. (2011) Increased Detection Sensitivity for KRAS Mutations Enhances the Prediction of Anti-EGFR Monoclonal Antibody Resistance in Metastatic Colorectal Cancer. Clinical Cancer Research, 17, 4901-4914. http://dx.doi.org/10.1158/1078-0432.CCR-10-3137

[35] Townsley, C.A., Major, P., Siu, L.L., Dancey, J., Chen, E., Pond, G.R., et al. (2006) Phase II Study of Erlotinib (OSI-774) in Patients with Metastatic Colorectal Cancer. British Journal of Cancer, 94, 1136-1143. http://dx.doi.org/10.1038/sj.bjc.6603055

[36] Santoro, A., Comandone, A., Rimassa, L., Granetti, C., Lorusso, V., Oliva, C., et al. (2008) A Phase II Randomized Multicenter Trial of Gefitinib plus FOLFIRI and FOLFIRI Alone in Patients with Metastatic Colorectal Cancer. Annals of Oncology, 19, 1888-1893. http://dx.doi.org/10.1093/annonc/mdn401

[37] Tournigand, C., Samson, B., Scheithauer, W., Lledo, G., Viret, F., Andre, T., et al. (2012) Bevacizumab (Bev) with or without Erlotinib as Maintenance Therapy, Following Induction First-Line Chemotherapy plus Bev, in Patients (pts) with Metastatic Colorectal Cancer (mCRC): Efficacy and Safety Results of the International GERCOR DREAM Phase III Trial. Journal of Clinical Oncology, 30, Article ID: LBA3500.

[38] Caponigro, F., Casale, M. and Bryce, J. (2003) Farnesyl Transferase Inhibitors in Clinical Development. Expert Opinion on Investigational Drugs, 12, 943-954. http://dx.doi.org/10.1517/13543784.12.6.943

[39] Wilhelm, S.M., Dumas, J., Adnane, L., Lynch, M., Carter, C.A., Schutz, G., et al. (2011) Regorafenib (BAY 73-4506): A New Oral Multikinase Inhibitor of Angiogenic, Stromal and Oncogenic Receptor Tyrosine Kinases with Potent Preclinical Antitumor Activity. International Journal of Cancer, 129, 245-255. http://dx.doi.org/10.1002/ijc.25864

[40] Boisvert-Adamo, K. and Aplin, A.E. (2008) Mutant B-RAF Mediates Resistance to Anoikis via Bad and Bim. Oncogene, 27, 3301-3312. http://dx.doi.org/10.1038/sj.onc.1211003

[41] Corcoran, R.B., Dias-Santagata, D., Bergethon, K., Iafrate, A.J., Settleman, J. and Engelman, J.A. (2010) BRAF Gene Amplification Can Promote Acquired Resistance to MEK Inhibitors in Cancer Cells Harboring the BRAF V600E Mutation. Science Signaling, 3, ra84. http://dx.doi.org/10.1126/scisignal.2001148

[42] Poulikakos, P.I., Zhang, C., Bollag, G., Shokat, K.M. and Rosen, N. (2010) RAF Inhibitors Transactivate RAF Dimers and ERK Signaling in Cells with Wild-Type BRAF. Nature, 464, 427-430. http://dx.doi.org/10.1038/nature08902

[43] Yeh, J.J., Routh, E.D., Rubinas, T., Peacock, J., Martin, T.D., Shen, X.J., et al. (2009) KRAS/BRAF Mutation Status and ERK1/2 Activation as Biomarkers for MEK1/2 Inhibitor Therapy in Colorectal Cancer. Molecular Cancer Therapeutics, 8, 834-843. http://dx.doi.org/10.1158/1535-7163.MCT-08-0972

[44] Tentler, J.J., Nallapareddy, S., Tan, A.C., Spreafico, A., Pitts, T.M., Morelli, M.P., et al. (2014) Identification of Predictive Markers of Response to the MEK1/2 Inhibitor Selumetinib (AZD6244) in K-ras-Mutated Colorectal Cancer. Molecular Cancer Therapeutics, 9, 3351-3362. http://dx.doi.org/10.1158/1535-7163.MCT-10-0376

[45] Abraham, R.T. and Gibbons, J.J. (2007) The Mammalian Target of Rapamycin Signaling Pathway: Twists and Turns in the Road to Cancer Therapy. Clinical Cancer Research, 13, 3109-3114. 
http://dx.doi.org/10.1158/1078-0432.CCR-06-2798

[46] Meric-Bernstam, F. and Gonzalez-Angulo, A.M. (2009) Targeting the mTOR Signaling Network for Cancer Therapy. Journal of Clinical Oncology, 27, 2278-2287. http://dx.doi.org/10.1200/JCO.2008.20.0766

[47] Liu, Q., Thoreen, C., Wang, J., Sabatini, D. and Gray, N.S. (2009) mTOR Mediated Anti-Cancer Drug Discovery. Drug Discovery Today: Therapeutic Strategies, 6, 47-55. http://dx.doi.org/10.1016/j.ddstr.2009.12.001

[48] Fan, Q.W., Cheng, C.K., Nicolaides, T.P., Hackett, C.S., Knight, Z.A., Shokat, K.M., et al. (2007) A Dual Phosphoinositide-3-Kinase Alpha/mTOR Inhibitor Cooperates with Blockade of Epidermal Growth Factor Receptor in PTENMutant Glioma. Cancer Research, 67, 7960-7965. http://dx.doi.org/10.1158/0008-5472.CAN-07-2154

[49] Khare, S. and Verma, M. (2012) Epigenetics of Colon Cancer. Methods in Molecular Biology, 863, 177-185. http://dx.doi.org/10.1007/978-1-61779-612-8 10

[50] Schaefer, M., Hagemann, S., Hanna, K. and Lyko, F. (2009) Azacytidine Inhibits RNA Methylation at DNMT2 Target Sites in Human Cancer Cell Lines. Cancer Research, 69, 8127-8132. http://dx.doi.org/10.1158/0008-5472.CAN-09-0458

[51] Susman, S., Tomuleasa, C., Soritau, O., Mihu, C., Rus-Ciuca, D., Sabourin, J.C., et al. (2012) The Colorectal Cancer Stem-Like Cell Hypothesis: A Pathologist's Point of View. Journal of B.U.ON, 17, 230-236.

[52] Vermeulen, L. and Snippert, J. (2014) Stem Cell Dynamics in Homeostasis and Cancer of the Intestine. Nature Reviews Cancer, 14, 468-480. http://dx.doi.org/10.1038/nrc3744

[53] Bertrand, F.E., Angus, C.W., Partis, W.J. and Sigounas, G. (2012) Developmental Pathways in Colon Cancer: Crosstalk between WNT, BMP, Hedgehog and Notch. Cell Cycle, 11, 4344-4351. http://dx.doi.org/10.4161/cc.22134

[54] Steinbach, G., Lynch, P.M., Phillips, R.K., Wallace, M.H., Hawk, E., Gordon, G.B., et al. (2000) The Effect of Celecoxib, a Cyclooxygenase-2 Inhibitor, in Familial Adenomatous Polyposis. New England Journal of Medicine, 342, 1946-1952. http://dx.doi.org/10.1056/NEJM200006293422603

[55] Dihlmann, S., Siermann, A. and von Knebel Doeberits, M. (2001) The Nonsteroidal Anti-Inflammatory Drugs Aspirin and Indomethacin Attenuate $\beta$-Catenin/TCF-4 Signaling. Oncogene, 20, 645-653. http://dx.doi.org/10.1038/sj.onc.1204123

[56] Sikandar, S., Dizon, D., Shen, X., Li, Z., Besterman, J. and Lipkin, S.M. (2010) The Class I HDAC Inhibitor MGCD0103 Induces Cell Cycle Arrest and Apoptosis in Colon Cancer Initiating Cells by Upregulating Dickkopf-1 and Non-Canonical Wnt Signaling. Oncotarget, 1, 596-605.

[57] Asklund, T., Kvarnbrink, S., Holmlund, C., Wibom, C., Bergenheim, T., Henriksson, R., et al. (2012) Synergistic Killing of Glioblastoma Stem-Like Cells by Bortezomib and HDAC Inhibitors. Anticancer Research, 32, 2407-2413.

[58] Fujishita, T., Aoki, K., Lane, H.A., Aoki, M. and Taketo, M.M. (2008) Inhibition of the mTORC1 Pathway Suppresses Intestinal Polyp Formation and Reduces Mortality in Apc ${ }^{\text {Delta716 }}$ Mice. Proceedings of the National Academy of Sciences of the United States of America, 105, 13544-13549. http://dx.doi.org/10.1073/pnas.0800041105

[59] Fre, S., Bardin, A., Robine, S. and Louvard, D. (2011) Notch Signaling in Intestinal Homeostasis Across Species: The Cases of Drosophila, Zebrafish and the Mouse. Experimental Cell Research, 317, 2740-2747. http://dx.doi.org/10.1016/j.yexcr.2011.06.012

[60] Voojis, M., Liu, Z. and Kopan, R. (2011) Notch: Architect, Landscaper, and Guardian of the Intestine. Gastroenterology, 141, 448-459. http://dx.doi.org/10.1053/j.gastro.2011.06.003

[61] Miyamoto, S. and Rosenberg, D.W. (2011) Role of the Notch Signaling in Colon Homeostasis and Carcinogenesis. Cancer Science, 102, 1938-1942. http://dx.doi.org/10.1111/j.1349-7006.2011.02049.x

[62] Meng, R.D., Shelton, C.C., Li, Y.M., Qin, L.X., Notterman, D., Paty, P.B., et al. (2009) Gamma-Secretase Inhibitors Abrogate Oxaliplatin-Induced Activation of the Notch-1 Signaling Pathway in Colon Cancer Cells Resulting in Enhanced Chemosensitivity. Cancer Research, 69, 573-582. http://dx.doi.org/10.1158/0008-5472.CAN-08-2088

[63] Strosberg, J.R., Yeatman, T., Weber, J., Coppola, D., Schell, M.J., Han, G., et al. (2012) A Phase II Study of RO4929097 in Metastatic Colorectal Cancer. European Journal of Cancer, 48, 997-1003.

http://dx.doi.org/10.1016/j.ejca.2012.02.056 
Scientific Research Publishing (SCIRP) is one of the largest Open Access journal publishers. It is currently publishing more than 200 open access, online, peer-reviewed journals covering a wide range of academic disciplines. SCIRP serves the worldwide academic communities and contributes to the progress and application of science with its publication.

Other selected journals from SCIRP are listed as below. Submit your manuscript to us via either submit@scirp.org or Online Submission Portal.
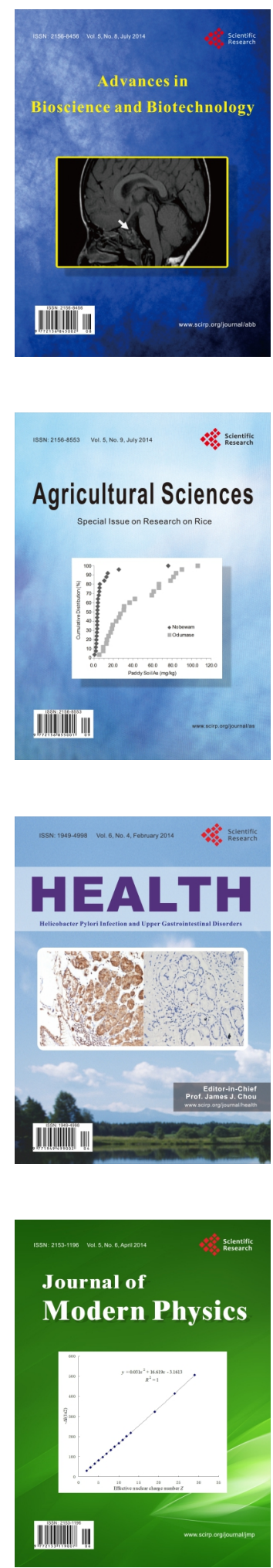
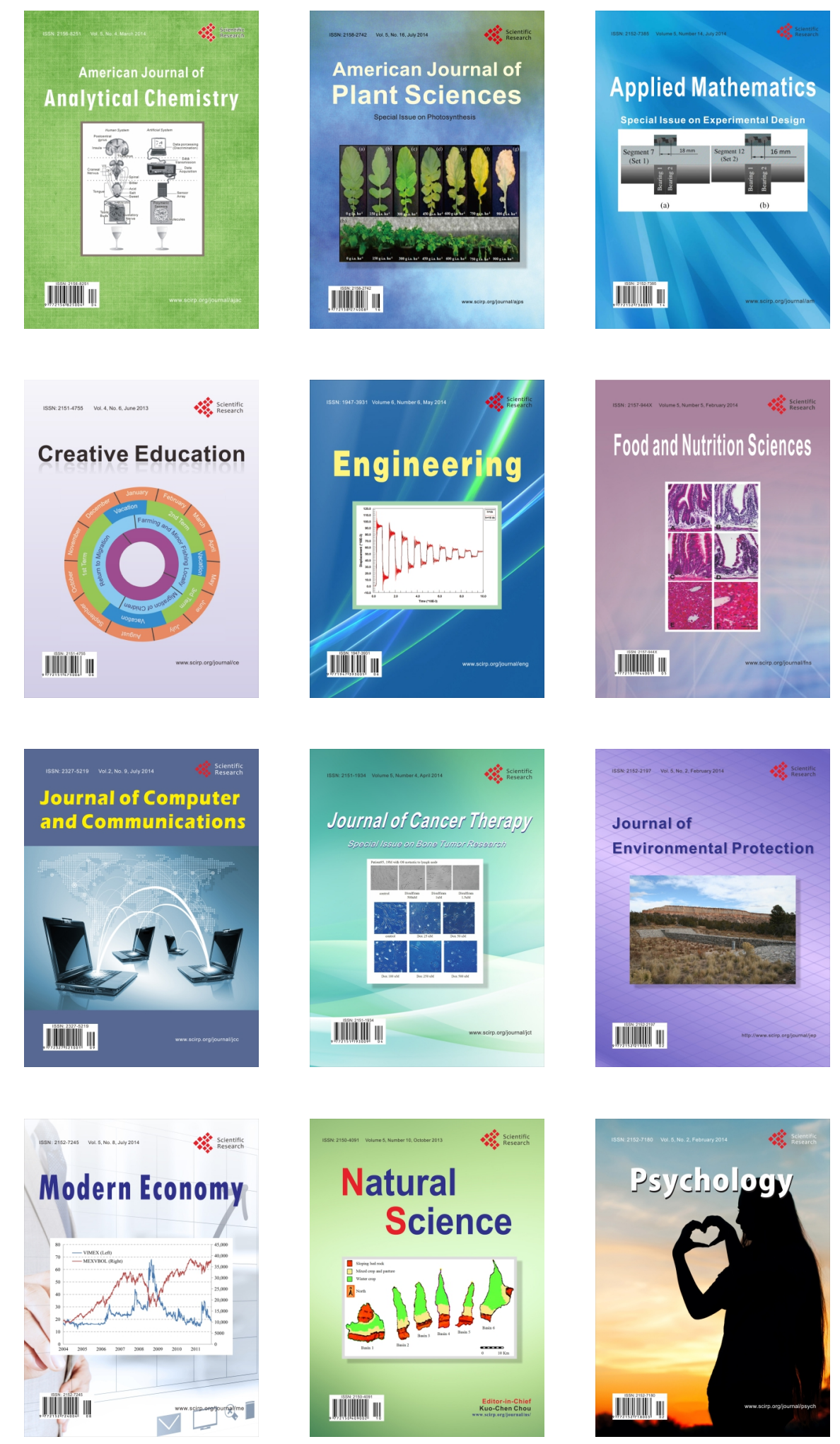